\title{
Exploration of Factors Influencing on Choice the Activity-Based Costing System in Iranian Organizations
}

\author{
Taha Ahmadzadeh (Corresponding author) \\ College of the Accounting \& Management, Sistan \& Blouchestan University, Zahedan, Iran \\ Tel: +98-914-166-3341Ｅ-mail: Tahausb@yahoo.com \\ Hossien Etemadi \\ College of the Humanity Science, Tarbit Modares University, Tehran, Iran \\ E-mail: Etemadih@modares.ac.ir, Hosein162@yahoo.com \\ Ahmed Pifeh \\ College of the Accounting \& Management, Sistan \& Blouchestan University, Zahedan, Iran \\ E-mail: Pifeh@adac.usb.ac.ir
}

Received: December 20, 2010 Accepted: January 13, 2011 doi:10.5430/ijba.v2n1p61

\begin{abstract}
As a tool for planning and control, costing systems play a considerable role in providing information needs for managers. Given the diversity of costing systems and simultaneous advancement of new costing systems, choosing a costing system may challenge managers. This research seeks to explore such organizational factors as organization size, industry type, cost structure, the importance of cost information, and products and services diversity on adopting Activity-Based costing (ABC) system in the listed companies of the Tehran Stock Exchange. Using logistic regression model from $33.5 \%$ of respondents in the sample, the results of this survey study indicates a positive relationship among cost structure, the importance of cost information and products and services diversity (in term of products and services liner numbers). It also indicates a negative relationship among the type of industry, organization size and product and services diversity (in terms of support diversity and volume diversity) with adopting the mentioned system. There was not any significant relationship between above organizational factors and choice of the $\mathrm{ABC}$ system.
\end{abstract}

Keywords: Costing Systems, Activity-based costing system, Overhead (Indirect) costs

\section{Introduction}

Present age of rigorous international competition and rapidly improving technology and improving information systems has forced companies to use new business management techniques. Market structures of products and services enforced companies to manage their costs according to business competition. Under severe competition, companies need to become leaner, responsive and agile, with ever-increasing efficiency and effectiveness. In order to retain the competitive status, a company should be able to provide high-quality services/products in a short period of time with lowest possible costs. In order to be able to lower costs, accurate cost information is critical for every aspect of business and it affects the pricing policies and performance reviews. This is not a critical issue for only manufacturing companies, it is also for service sector companies (Baykasoglu and Kaplanoglu, 2008).

In a rigorous business environment, manufacturing and supply services have become very hard to maintain satisfactory returns or profits. Therefore, the role of cost estimation for products and services has become more critical. Before the modern business management times, accounting was being just used to record the cost of products and/or services. However, the important role of cost estimation and cost information appeared after the advent of modern business management techniques. This is especially because the traditional cost systems are known to distort the cost information by using traditional overhead allocation methods. However, decision makers, assuming information is relevant, prefer more accurate product cost information to less. As a result, a gap has emerged between the accounting information gathered and the modern business management (Baykasoglu and Kaplanoglu, 2008).

Many business management concepts have been developed since the global competition had become serious. Organizations have started to practice their improvement of competitiveness. In order to achieve this goal they have 
started to use modern and advanced process and cost management techniques such as Activity-Based Costing, Kaizen Costing and Total Quality Management (Baykasoglu and Kaplanoglu, 2008).

The management accountants for consolidation of their real position as an active member of organization used the best of their efforts to innovate the best ways to answer the necessities of organization information. In this direction, many problems regarding to management accounting two decades ago to pave the way for the new world and compatibility with the changes happening nowadays, has provided (Osmani and Yousefian, 2000).

The Activity-Based Costing system as one of the best costing systems was introduced by two researchers of the Harvard University named Robert S. Kaplan and Robin Cooper for the first time. The above system makes the strategic decision like costing the products and determining the optimized component possible by the correct measurement of the cost of costing objects. Furthermore, it provides appropriate management by representing the useful non-financial information associated to organization's process and gives numerous guidelines in order to improving the performance of organization activities (Osmani and Yousefian, 2000).

The mentioned system is one the modern costing system of production and services that meet the needs of the costs correct compute of production, improving the production process, deletion of activities of the without added-value, recognition of cost drivers, control improvement, reduction of the cost production, operational programming and determining the commercial ways for economical entities. This system dissects the causes of costing rather than discovering the causative relationship and provides the improvement, omission and correction of that if there is no justifiable philosophy, applicants or the added-value (Horengern et al, 2006, p.80).

With using the measure adoption or non-adoption of the $\mathrm{ABC}$ system, this paper examines the extent to which different contextual factors (such as: Industry type, size of the organization, cost structure, importance of cost information and products and services diversity) influence the choice of $\mathrm{ABC}$ system by above measure.

The paper consists of ten sections. The next section considers perspective of ABC philosophy. Section 3 include "Criticism on the management accounting in Iran", section 4 summarizes the previous studies relating to this research and the following section provides a need of doing research, the research hypotheses are presented in section 6 , section 7 present the research design and data collection, section 8 include: Analysis Method, Research Model and Variables Measurement, sections 9 and 10 presents respectively finding research and summery and conclusion.

\section{A perspective of Activity-based Costing Philosophy}

In the late of 1960s and early of 1970s, some accounting writers pointed at the relationship between activity and cost. But in 1980 the collegiate assemblies attraction was absorb due to reflection common system inefficiency in representing accurate costing data. This attraction was mainly based on 3 major factors:

The first was a new change happened for the introduction of technology of the modern productive activities in different countries (Namazi, 1999).

The second was in 1980s the philosophy of many mangers underwent changes bedside, profitability, competition in global level, the customer's satisfaction enhancement, emphasis on production quality control and reduction of costing had become the main targets of managers (Namazi, 1999).

The third some of the accounting writers elucidated the different roles of technology and viewpoints of managers. The mentioned writers claimed that traditional industrial accounting system is not only irresponsible for the manager's requirement but also using the collected information from that leads to an incorrect decisions. Consequently, the writers tried to introduce a new system titled Activity-Based Costing (Namazi, 1999).

A requirement of practical data about costs, paved the way for the advent of Activity-Based Costing. This new trend was remarkably for presenting precious information to obtain the main purpose in and out of the organization (Namazi, 1999).

This system has two main viewpoints (Namazi, 1999):

- It's the representative of allocated costs from sources to activities and from activities to cost objects. In other words, its main assumption, that cost objects need activities and activities needs sources.

- The responsibility is the organizational demand to information about the effective factors on activities. In other sense, what factors trigger doing of tasks and how desirable it can be done.

\section{Criticism on Management Accounting in Iran}

Accounting systems of developing countries such as Iran always has some problem; because they are follow the developed countries. In Iran there have been severed factor influencing accounting systems. There are as follows: 
- Misunderstanding of the management accounting information for improving organizational efficiency. This matter has devoid of the following factors: operational turn over, accountants related to the production process, accurate information about capability of product lines, identification in costs behavior, using appropriate bases for allocating overhead costs, using budgeting mechanism related to account contents, variances compute and proving management reporting in appropriate periods (Etemadi and Shamszaeh, 2005).

- $\quad$ Lack of the IIMA (Note 1). In Iran there are such as IACPA (Note 2) and IICA (Note 3), but there is not organization or entity that can call IIMA. We don't have such organization so we shouldn't expect that management accounting be defined separately from financial accounting.

- Lack of interaction among experts and academics. Problems of accounting generally and management accounting particularly is based on lack of silks of employee and lack of interaction between experts and academics, because academics don't put innovation on profession and experts neglect the academics explorations.

- Insufficient education in the universities. In Iran, cost and management accounting are not properly taught. These important courses are taught in form of brief pamphlet.

\section{Previous Studies}

The key concept in contingency based research has been the concept of fit whereby contextual factors and aspects of an accounting system must somehow fit tighter for an organizational to be effective (Al-Omiri, Drury, 2007). In addition to, contingency theory suggests that the need for efficient organizational structures and processes and competent management accounting systems is contingent on a number of organizational and environmental characteristics (Sartorius, Eitzen and Kamala, 2007). Identified two forms of fit relating to structural contingency theory, are the selection and interaction approaches.

The former examines the relationship between contextual factors and organization structure without examining whether this context-structure relationship affects performance. In contrast, the interaction approach seeks to explain variations in organizational performance from the interaction of organizational are assumed to have varying degrees of fit the task of the researcher is to show that a higher degree of fit between context and structure is associated with higher performance (Al-Omiri and Drury, 2007).

In terms of management accounting control systems research the vast majority of studies have adopted the selection approach to fit, whereby characteristics of the accounting system represent the dependent variable. The literature review relating to product costing contingency research indicated that virtually all of the research has concentrated on concentrated on contextual factors influencing the adoption or non-adoption of ABC systems (Al-Omiri and Drury, 2007).

With regards to the above explanation, most of the done research in accounting management in this domain is the sectional type. As a result, we will present an abstraction of the done researches in this domain:

The researches has shown that variables such as organization size, organization life cycle stage, cost structure, competition intensity, economical crisis, importance of the cost information, innovation, support of management levels, structure and the strategy of the organization, internal performance measures with using and implementation of the $\mathrm{ABC}$ system have had positive and significant relationship (Askarany, Yazdifar \& Askary, 2009; Kallunki \& silvola, 2008; Sartorius, Eitzen \& Kamala, 2007; Mealah \& Nasir Ibrahim, 2007; Al-omiri \& Drury, 2007; Drury \& Tayles, 2005; Askarany \& Smith, 2003; Golsselin, 1997; Chongrukust, 2002 and Abernthy et al, 2001) On the other hand, the using and implementation of the above system with variables such as the activity type, levels of the fixed costs, production/service diversity and technology have had a negative relationship (Askarany, Yazdifar \& Askary, 2009; Al-omiri \& Drury, 2007; Drury \& tayles, 2005 and Alberntthy et al, 2001).

\section{The Need of Doing Research}

Concrete information which the fountain for their demand is the need of decision-maker, also relate and useful information is the result of an efficient information system. We know that cost management along with quality fundamental and moment challenge to managers. With regards to increasing levels of indirect cost among the production factors, the allocated ways of these costs to cost objects are considered gratefully remarkable that studying and research for them are so essential. In this way, management information systems entered into the business world and faced with diverse consequences.

Activity-Based Costing system was one of the solutions that its right implementation and performance had many advantage for the users. The previous done research in Iran has focused all its attention on the conditions of ABC system using and proving the fact this system supplies move useful and accurate data rather than traditional costing system in 
Iranian companies. Therefore, in this research we put our best foot forward to the relationship detect a series of organizational factors with implementation and choice of the mentioned system among the listed companied in the Tehran Stock Exchange.

\section{Research Hypotheses}

A literature review was undertaken to identify the potential contextual factors that may influence the level of sophistication of product costing systems. The following contextual factors are examined:

-Industry type

-Size of the organization

-Cost structure

-Importance of cost information

-Products/Services diversity

\subsection{Industry type}

Shields (1997), argues that the design and effectiveness of cost accounting information and systems are conditional on characteristics of industries. The diffusion of innovation literature, also implies that organizations within an industry sector may imitate other organizations. Therefore, the imitation process may result in similar accounting systems being adopted within specific business sector. $\mathrm{ABC}$ was initially introduced in manufacturing organizations. Thus, mimicking behavior suggests that manufacturing organizations may be more likely to adopt sophisticated costing systems (Al-Omiri and Drury, 2007). Therefore, the following hypothesis is formulated:

$\mathrm{H1}$ : There is a positive relationship between the using and adoption $\mathrm{ABC}$ systems and industry type.

\subsection{Size of the organizational}

Size has been found to be an important factor influencing the adoption of more complex administration systems. Previous studies have also noted a positive relationship between company size and the adoption of ABC systems. A possible reason for this is that larger organizations have relatively greater access to resources to experiment with the introduction of more sophisticated accounting systems (Al-Omiri and Drury, 2007). Therefore, the following hypothesis is tested:

$\mathrm{H} 2$ : There is a positive relationship between the size of the organization and the using and adoption $\mathrm{ABC}$ system.

\subsection{Cost structure}

A review of European surveys relating to cost structures of manufacturing companies by Brierley et al (2001) indicated that direct material costs tend to be higher than indirect costs. They conclude that if indirect costs make up a relative small proportion of total costs in some industries it may not be worthwhile investing in sophisticated accounting methods to allocate indirect costs. Conversely, where the proportion of indirect costs is low, direct costing may be appropriate or, if indirect costs are assigns to cost objects, unsophisticated traditional costing systems may not result in the reporting of seriously distorted costs (Al-Omiri and Drury, 2007). Thus, the following hypothesis is tested:

H3: There is a positive relationship between the proportion of indirect costs within an organization $s$ cost structure and the using and adoption $\mathrm{ABC}$ system.

\subsection{Importance of cost information}

Even if sophisticated cost systems could substantially reduce product cost distortions it is unlikely to be helpful unless a firm can actually utilize better cost information in its decision-making process. Firms mainly relying on cost information for inventory valuation/profit measurement rather than decision-making purposes may rely on less accurate cost information derived from simplistic costing systems. The differing needs by organizations for accurate cost data for strategic decisions and cost reduction may affect $\mathrm{ABC}$ adoption. Factors affecting the decision usefulness of cost information include the firm's use of cost data in pricing decisions, cost reduction efforts and the need for special cost studies (Al-Omiri and Drury, 2007). The following hypothesis is therefore tested:

H4: There is a positive relationship between the importance of cost information and using and adoption of the ABC.

\subsection{Products and services diversity}

Product diversity leads to a higher potential for cost distortion and applies when products consume activity resources in different proportions. Greater product diversity requires more sophisticated costing systems to capture the variation in resource consumption by different products. Point out that product diversity includes support, process and volume diversity. Support diversity refers to varying support given to each product by various support departments whereas process diversity refers to differences in consumption among all identifiable activities relating to product design, 
manufacture and distribution. Volume diversity occurs when products are manufactured in different batch size thus affecting how batch level cost should be assigned to products. Product diversity determines production process complexity resulting in more activities being required to manufacture them. Thus, to measure the resource consumption of different products in a complex setting, sophisticated costing systems are required (Al-Omiri and Drury, 2007). Based on the above discussion the following hypothesis is tested:

H5: There is a positive relationship between higher levels of products diversity and using and adoption of the ABC.

\section{Research Design and Data Collection}

This research is applicable in goals respect and research design is descriptive in survey. This is descriptive owing to representing the existent situation and it is surveying because of to collection form statistical source by means of questionnaire to take matter into consideration.

In the presented research the statistical community including listed companies in the Tehran Stock Exchange. This statistical community covers 354 companies according with market management statement (statistic and information bureau in the year of 2009 (or 1387 of Iran)) Tehran Stock Exchange organization. By omitting the investment companies such as Holding and Leasing has been restricted due to marginal cost and no need to costing systems like traditional and modern. Therefore, the real statistical community includes 301 companies. As far as doing every scholarly research concerns with time and cost, the possibility of total exploration of community based on statistics is most of the time impossible. Thus, the sample choice and sampling method is indispensable for the research. The sampling method in this research is an accidental simple kind and numbers of statistical sample has designated by Morgan diagram, case 170.

The main tool in data collection to this research like other surveyed researches is questionnaire. Due to sample size, 170 postal questionnaires has been sent to the selected companies that audience was of the financial managers. Of this rate 57 cases returned all which were usable. Therefore in this research the response coefficient is $33.5 \%$ that in comparison with the performed research in this respect have a remarkable ratio, because the acceptable rate of accountability in this respect approximately $20 \%$ has been declared (Krumwiede, 1998).

\section{Analysis Method, Research Model and Variables Measurement}

In this research the following test are being used to prove the supposition and also research model and variables measurement:

- Reliability test of the Cronbach's Alpha

- $\quad$ Logistic regression model

- $\quad$ research model and variables measurement

The following will be delineated and expounded discretely:

\subsection{Reliability test of the Cronbach's Alpha}

The goal and meaning of evaluation reliability and questionnaire stability is that if this research done again by other researcher or by the same researcher in different places and times will face similar results with the existent. Often for evaluation the questionnaire reliability, Cronbach's Alpha is used (Therandick, 1990, p.234).

As the only related question about importance of cost information, volume diversity and support diversity are 5-point likert's scales. So Cronbach's Alpha only for their cases used for evaluation that they are consequently equals to 0.742 , 0.752 and 0.618 . Because two first cases has Alpha more than $70 \%$ so we can say that they have considerable Reliability, but they are different views about the last on that we can point on Hair et al (1998) and Nunally (1978) who determine the acceptable level as are respectively $60 \%$ and 50\% (Al-Omiri and Drury, 2007). Then with the use acceptable extension of Alpha by researcher and academics we can say that this case also has sufficient Reliability.

\subsection{Logistic regression model}

In this research to analyze the statistical data use logistic regression model with the application of the SPSS software. Logistic regression analysis is applied when the dependent variable has only 2 results and can accept one of the values of zero or one, which the one number equivalent to incident occurrence and zero stands for incident occurrence impossibility, so considered as the more powerful tool to discriminated analysis. This statistical way besides designating the variables coefficients in equation, relationship and significant, shows other statistics such as $\chi^{2}$ and Wald (Momeni, 2010, p.158).

Considering the above details, in this paper incident occurrence the equal with choice and lack of incident non-selected meaning and application of this system is. 
8.3 Research model and variables measurement

$\mathrm{Y}=b_{1}+b_{2}$ FACTOTY $+b_{3}$ SIZE $(\mathrm{REV})+b_{4}$ SIZE $($ ASSETS $)+b_{5}$ INDCOS $+b_{6}$ COSTIMP $+b_{7}$ PRODIV (NP/SL) + $b_{s}$ PRODIV (VOLDIV) $+b_{9}$ PRODIV (SUPDIV) $+\mathrm{e}$

Where:

Y: is equal to 1 if company has used and selected of the ABC and otherwise equal to 0, FACTORY: Industry type (is equal to 1 if its production and otherwise is equal to 0), SIZE: size measured by annual Revenue and Assets Total, INDCOS: Indirect costs as a percentage of total costs, COSTIMP: Importance of Cost Information, PRODIV (NP/SL): Numbers of Production/Services Lines, PRODIV (VOLDIV): volume Diversity, PRODIV (SUPDIV): Support Diversity and E: residual error term.

\section{Research Findings}

In this the research, Implementation of system according to system choice definition by Bjornenak (1997) indicates there must be given a definition already to determine $\mathrm{ABC}$ system choose. In this case the selection and implementation system consists of two levels of system implementation that means complete and in the under implementation. In this part the explanation of the implemented statistical ways that is logistic regression model to show the kind of the relationship between dependent and independent variables will be given.

Due to results of the logistic regression model in the table (2), the following will describe the results of each hypothesis:

$<$ Tables 1,2 about here $>$

\subsection{Industry type and adoption of the ABC system}

This study seeks to establish if the economic sector in which the company operates has any significance for the implementation of $\mathrm{ABC}$ systems. It was expected that manufacturing companies are more likely to adoption $\mathrm{ABC}$ than companies within other sectors.

The used statistical method for research shows the negative relationship between Industry type (manufacturing) and system choice $\mathrm{ABC}$. In other words, the results show this fact that the system choice in service companies is more abundant than manufacturing companies. This result with the proclamations of Cooper \& Kaplan claiming that boosting up this system in service sector or non-manufacturing, which is more in accordant. The major reason that service companies goes toward advanced management accounting techniques is also the remarkable role of overhead costs in cost structure and can say that manufacturing companies dispose their stress on direct cost especially the raw material for the cost making politics and more competition and also based on this rise and down the selling price. So, laying much emphasis on indirect cost are scantly regarded and based on them, the manufacturing companies react rarely to sophisticated systems implementation. Totally, results didn't support the research hypothesis and reject it.

\subsection{Size of the organization and adoption of the ABC system}

In this study, Firm size has been measured both by the annual revenue and assets total. The results of the done research related to this variable in different countries show that positive relation among organization size and choice and implementation of advanced management accounting techniques but In this research in contrast with other researches, size (each 2 parameter) had a negative $(-0.49,-0.469)$ relationship and insignificant with implementation of the $\mathrm{ABC}$ system. In other sense, the choice and implementation of this system among other intermediate companies and small ones are more common rather than big companies.

The reasons, why big Iranian companies have not attempted to implement this system, can be traced in economical crisis, lack of external competition and also no place for themes in the world. According to this, although the deployed companies in Asian countries in different levels of introductory or less and these sorts of companies have comprehended the management accounting information to a better efficiency, as a result react very seldom than to innovations. Totally, results didn't support the research hypothesis and rejects it.

\subsection{Cost structure and adoption of the ABC system}

It's obvious that the main goal professional $\mathrm{ABC}$ selection is accurate allocation of overhead costs. Because direct costs are very easily traceable to product and services so are not good reasons to this kind of systems implementation. Nowadays overhead costs has significant portion of cost structure in compare to direct labor so organizations have to go forward to $\mathrm{ABC}$ implementation for computing accurate cost of products and services. However, suggested hypotheses related to this variable shows that there is positive relationship (0.389) between cost structure and this ABC adoption. Totally, results support the research hypothesis.

\subsection{Importance of cost information and adoption of the ABC system}

Making appropriate decisions for solving a problem or suggesting new way needs information about the issue and goal. 
Cost information also are from this kind that management level of organization feel need for making decisions about product pricing, competition and analysis of profitability of customer, product and services. So we can say that cost information is important information. Discussion of relationship between importance of cost information and choice and implementation of advanced management accounting techniques are considerable as inaccurate allocating of overhead costs, because of their high portion in cost structure cannot degree of relevancy raises the need of implementing professional costing systems. Research results in this field indicate positive relationship (0.056) between to variables. It is shown that existing relationship is closer to non-relation and this argues that examining sample often evaluated cost information as a critical and important component.

Totally, results support the research hypothesis.

\subsection{Production/Services diversity and adoption of the ABC system}

Nowadays it is so hard to compete in the market by producing only one product or service. So organizations for remaining in current competition advance their operation and as a result Number of products and services increases. Cooper in 1988 argues that product and services diversity lead to overhead cost increase and this is a reason for growth of costs. Growth of overhead costs and change in their natural raises the need of relevant and timely information. Consequently, inaccurate allocation of overhead cost is a sign of danger of depression for organization and these reasons are true not only about using $\mathrm{ABC}$ system, but also are important for supporting, decision-making and improving production overhead management. On other hand, when consumption source of product unit level has not direct relation with other sources, traditional system will report inappropriate costing information. So in this research hypothesis is about the existence of positive relationship among high level of products and services diversity and choice and implementation of the $\mathrm{ABC}$ system. This hypothesis describe in 3 following ways:

\subsubsection{Numbers of Production/Services Liners}

Diversity of products and services in this dimension is evaluated by the number of product and service line. Results of regression model in this method is regulator to positive relationship $(0.321)$ existing between product and services diversity. On the other words, with increase in diversity of product and services, the need for this system will be increase.

As the production and service sites has been increased, consequently unit incentive such as direct labor hours or numbers of production cannot deal with accurate allocation of overhead costs, so companies tends to use this kind of systems. Totally, results support the research hypothesis.

\subsubsection{Volume Diversity}

Product and diversity in this approach is determined by combination of difference in product and service selling volume. Whether all production/services are in similar volumes or volume varies for each of the items produced/sold. Results of the regression model shows negative relationship (-0.326) between products/services diversity and adaption of the ABC system.

Since the main reason of change in errors cost is because of difference in competition level, competition will lead to increase in errors cost and this errors will lead to making weak decision in product such as risky selling of losable product or inappropriate product costing that finally will lead to halt of product and service lines (Cooper et al, 2005, pp.64-65). If we interpret the above explanation as innovative competition, we will reach to the change in methods of selling and all of these implications is results of using an inappropriate system. With regard to the above explanation and model results, position and condition of active companies in the Tehran stock exchange. Totally, results didn't support the research hypothesis and reject it.

\subsubsection{Support Diversity}

Product and service diversity in this approach as its clear form its name is computed by degree of diversity or difference in using services and supporting source or in the other word as the difference in use of this source by product and service becomes substantial and critical, we can say that there is substantial supporting diversity. Results of the regression model shows, negative relationship (-0.062) among products/services diversity and using of the ABC system. From this point of view, the reason of why with the high support diversity these companies reaction so infrequently to the implementation of this system is that, organization just focus on the direct cost of unit and patch levels and neglected product support level. Totally, results didn't support the research hypothesis and reject it.

\section{Summery and Conclusion}

This research is reviewing some organizational relation such as the industry type, size, cost structure, importance of cost information and product and services diversity with implementation and choice of the $\mathrm{ABC}$ system through the listed companies in the Tehran stock exchange statistical sample becomes 301 after omitting investment companies such as 
Holding and Leasing and as sample volume determined 170 in regard Morgan table. Research data accumulated by the questionnaire which sent the companies addresses acquired from their web sites. The results of research by logistic regression model with the $33.5 \%$ response indicate positive relationship in the cost structure, importance of cost information and product/services diversity (NP/SL), and negative relationship in the industry type, size and product/services diversity (volume and support) with implementation and choice of the ABC system. Also cannot reach the results indicating significant relationship between above organizational factors and using the $\mathrm{ABC}$ system.

Despite, this study has provided additional insights into areas relating to factors influencing the adoption of ABC system and extended the scope of future research. Considerable efforts have been taken to minimize the limitations and remedy the deficiencies of previous studies. It is hoped that this paper will motivate researchers to undertake further research in the areas suggested.

Besides attempting to improve the methods of measurement the variable, future research should consider incorporating other important variables that have been omitted from this study but which are likely to influence cost system design. The most notable omitted independent variables are organizational such as top management support, resistance to change by providers and users of accounting information, lack of relevant employees' skills, competition, organizational life cycle stage, economical crisis, quality of information technology and level of the fixed costs.

\section{References}

Abernethy et al. (2001). Product diversity and costing system design choice: field study evidence. Management Accounting Research, 12, 261-279, doi: 10.1006/mar.2001.0168, http://dx.doi.org/10.1006/mare.2001.0168

Al-Omiri, Mohammad \& Drury, Colin. (2007). A Survey of factors influencing the choice of product costing systems in UK organizations. Management Accounting Research, 18, 399-424, doi:10.1016/j.mar.2007.02.002, http://dx.doi.org/10.1016/j.mar.2007.02.002

Askarany, Davood \& Smith, Malcolm. (2003). The Relationship between Technological Innovation, Activity-Based Costing and Business Size. Informing Science, 865-882.

Askarany, Davood., Yazdifar, Hassan \& Askary, Saeed. (2009). Supply Chain Management, Activity-Based Costing and Organizational Factors. International Journal Production Economics, 1-11.

Baykaso glu, Adil \& Kap lanoglu. (2008). Application of Activity-Based Costing to Land transportation company: a case study, International Production Economics, 116, 308-324.

Bjornenak, T. (1997). Diffusion and Accounting: The case of ABC in Norway. Management Accounting Research, 8, 3-17. doi:10.1006/mare.1996.0031, http://dx.doi.org/10.1006/mare.1996.0031

Chongruksut, Wiriya. (June 2002). The Adoption of Activity-Based Costing in Thailand. Unpublished doctoral dissertation, Victoria University.

Cooper et al. (2005). Activity-Based Costing (AICPA). Azizi \& Modares, Ahmad (Trans), Tehran: Audit organization.

Drury, Colin \& Tayles, Mike. (2005). Explicating the design of overhead absorption procedures in UK organizations. The British Accounting Review, 37, 47-84. doi:10.1016/j.bar.2004.08.003, http://dx.doi.org/10.1016/j.bar.2004.08.003

Etemadi, Hosien \& shamszadeh, Bgher. (2005). Definite of production costing system problems on the Iranian steel industry. SID, 8(2), 35-51.

Gosselin, Maurice. (1997). The effect of strategy and organizational structure on the adoption and implementation of Activity-Based Costing. Accounting, Organizational and Society, 22(2), 105-122. doi:10.1016/S0361-3682(96)00031-1, http://dx.doi.org/10.1016/S0361-3682(96)00031-1

Horengren, Charles T and et al. (2006). Cost accounting: A managerial emphasis. Parsaian, Ali (Tran), Tehran: Tarmeh publications.

Kallunki, Juha-Pekka \& Silvola, Hanna. (2008). The effect of organizational life cycle stage on the use of Activity-Based Costing. Management accounting research, 19, 62-79. doi:10.1016/j.mar.2007.08.002,

http://dx.doi.org/10.1016/j.mar.2007.08.002

Krumwiede, K.R. (1998). The Implementation stages of activity- based costing and the impact of contextual and organizational factors. Journal of Management accounting Research, 10, 239-277.

Momeni, mansor. (2010). Statistical analysis by the SPSS. Tehran: New Book publications (p.158). 
Namazi, Mohammad. (1999). Investigating ABC system in management Accounting and its behavioral consideration. Auditing and Accounting Reviews (Iran), 26-27, 71-106.

Osmani, Mohammad Ghasim \& yousefian, mehrdad. (2000). Investigating using condition of ABC system in listed companies of the cement in the Tehran Stock Exchange. Unpublished master's thesis, Shahid Baheshti University, Tehran, http://irandoc.com, No: 015413.

Sartorius, K., Eitzen, C \& Kamal, P. (2007). The design and implementation of Activity-Based Costing: A South Africa Survey. Meditari Accountancy Research, 15(2), 1-21.

Therandick, Robert L. (1990). Applied psychometrics. Human, Ali Hidar (Tran), Tehran: Tehran University Publications.

\section{Notes}

Note 1. Iranian Institute of Management Accounting

Note 2. Iranian Association of Certified Public Accountants

Note 3. Iranian Instituted Accountant

Table 1. Analysis of current position and Adoption of the ABC system by Industry type

\begin{tabular}{|c|c|c|c|c|c|c|}
\hline \multirow[t]{2}{*}{ Industry type } & \multicolumn{5}{|c|}{ Current position of the $\mathrm{ABC}$ system } & \multirow{2}{*}{$\begin{array}{l}\text { Total } \\
(\%)\end{array}$} \\
\hline & Implementation $\%$ & $\begin{array}{c}\text { Under } \\
\text { Implementation \% }\end{array}$ & Consider $\%$ & Non-Consider $\%$ & Reject $\%$ & \\
\hline Manufacturing & 6 & 18 & 48 & 22 & 6 & $\begin{array}{c}50 \\
(87.7)\end{array}$ \\
\hline Service & 14 & 14 & 43 & 29 & 0 & $\begin{array}{c}7 \\
(12.3)\end{array}$ \\
\hline Total & 4 & 10 & 27 & 13 & 3 & $\begin{array}{c}57 \\
(100)\end{array}$ \\
\hline Total $\%$ & 7 & 17.5 & 47.5 & 23 & 5 & 100 \\
\hline $\begin{array}{c}\mathrm{ABC} / \text { Non- } \mathrm{AB} \\
\mathrm{C} \%\end{array}$ & \multicolumn{2}{|c|}{24.5} & \multicolumn{3}{|c|}{75.5} & 100 \\
\hline
\end{tabular}

Above table shows current position of ABC systems through the examining Sample in general and details. In other words, table shows that $87.7 \%$ and $13.3 \%$ sample forms manufacturing and service companies and also shows current system position in detail (Industry) and general (sample). For example 18\% of manufacturing companies are implementing the $\mathrm{ABC}$ system or $4 \%$ of sample has done the implementation completely and finally above table shows the percentage of choosing or not choosing the system as a unit set $24.5 \%$ and $75.5 \%$. 
Table 2. Logistic regression analysis with the dichotomous variable $\mathrm{ABC} /$ non- $\mathrm{ABC}$ as the dependent variable $(\mathrm{N}=57)$

\begin{tabular}{|c|c|c|c|c|c|c|c|}
\hline \multicolumn{8}{|c|}{ Variables in the Equation } \\
\hline Variables & $\begin{array}{c}\text { EXP-Sig } \\
n\end{array}$ & B & S.E. & Wald & d.f & Sig. & $\begin{array}{c}\operatorname{Exp}(\mathrm{B} \\
)\end{array}$ \\
\hline Industry Type & + & -.340 & 1.047 & .106 & 1 & .745 & .712 \\
\hline Size(REV) & + & -.049 & .378 & .017 & 1 & .896 & .952 \\
\hline Size(ASSETS) & + & -.469 & .613 & .586 & 1 & .444 & .626 \\
\hline INDCOST & + & .389 & 2.032 & .037 & 1 & .848 & 1.475 \\
\hline COSTIMP & + & .056 & .388 & .021 & 1 & .885 & 1.058 \\
\hline $\mathrm{NP} / \mathrm{SL}$ & + & .321 & .351 & .837 & 1 & .360 & 1.379 \\
\hline VOLDIV & + & -.326 & .239 & 1.867 & 1 & .172 & .722 \\
\hline SUPDIV & + & -.062 & .295 & .044 & 1 & .834 & .940 \\
\hline \begin{tabular}{l}
\multicolumn{2}{c}{ Constant } \\
Chi-Square \\
3.533 \\
Nagelkerke R \\
Square \\
Hosmer and Lemshow $\quad .089$ \\
$X^{2}=11.402$ \\
Per Cent Correctly Classified $\quad 75.4 \%$
\end{tabular} & & .519 & 2.918 & .032 & 1 & $\begin{array}{c}.859 \\
0.897 \\
0.18\end{array}$ & 1.681 \\
\hline
\end{tabular}

A positive sign for logistic regression coefficient indicate that the variable is positively related to $\mathrm{ABC}$ adoption.

The Chi-square statistic shown in above tablet is comparable to F-test in multi regression. The Chi-Square has shown that relationship between variables statistically not-significant. The Hosmer and Lemeshow goodness of fit value (.18) measures the correspondence of the actual and predicted values of the dependent variable. This statistic tests the hypothesis that the observed data are significantly different from the predicted values. Thus, a non-significant statistic indicates that the model does not differ significantly from the observed.

Nageelkereke R Square (.089) attempts to quantify the proportion of explained variation in the logistic regression model. It is similar in intent to the $R^{2}$ in a linear regression model.ol

Exp (B) shown in the final column above tablet is an indicator of the change in odds resulting from a unit change in the indicator. Value greater than 1 indicate that as the predictor increases, the odds of the outcome occurring increase; conversely, a value less than one indicate that as the predictor increases, the odd of the outcome occurring decrease. This is consistent with the signs of the regression coefficients. 